\title{
Challenges of Converting an In-person Dance Course to a MOOC Course*
}

\author{
Ángela Rocío Chantre Astaiza** \\ Claudia Patricia Burbano Astaiza ${ }^{* * *}$ \\ Mario Fernando Solarte Sarasty ${ }^{* * *}$
}

Received: 15/10/2019 - Approved: 27/08/2020
https://doi.org/10.22395/rium.v20n38a7

\begin{abstract}
This article presents the design experience of the "Folk dance as cultural heritage" course, which is offered to undergraduate students from University of Cauca the "massive online course" modality. It shows the main challenges faced in the exercise of the integration of two in-person courses, one practical and one theoretical, and its process of transformation into a MOOC. The course was designed for two academic credits with six hours of dedication per week and is offered a s a elective (non-mandatory) class of the Integral Social and Human Formation (FISH) component, through a space in the MOOC Open edX platform. The integration process of the two in-person courses and their transformation into a MOOC, brought with it several challenges related to the adjustment of contents, academic activities and evaluation. This article presents how these challenges were faced in this experience. It is worth mentioning that one of the results obtained in this research is associated with the contribution of the research to the first folk dance course in MOOC modality in Latin America, what makes it an innovative educational proposal that allows the rescue of culture through the adaptation of traditional educational contents.
\end{abstract}

Keywords: cultural heritage; folkl dance; massive online course; MOOCs.

Article derived from the research project "MOOCMenTES - Capacity Building for the Management of MOOCs for professional Training, Rural Development and New Generations of Rural Students in Improving their Transition to Higher Education"; approved and sponsored by the Ministry of Colombian Education

** Ph. D. in Business Economics, Full Professor at University of Cauca, Department of Tourism Scienc. E-mail: achantre@unicauca.edu.co. Orcid:https://orcid.org/0000-0002-4031-3816

*** Master in Education, Majoring in Research. Non-Tenured Full-Time Teacher, Department of Sports, Recreational and Physical Activity, University of Cauca. E-mail: cpburbano@unicauca.edu.co. Orcid: https://orcid. org/0000-0002-7235-1294

**** Ph. D. in Telematics Engineering and Full Professor at University of Cauca, Department of Telematics Engineering. Email: msolarte@unicauca.edu.co. Orcid: https://orcid.org/0000-0002-3600-7592 


\section{Retos de la transformación de una clase presencial de danza a un curso MOOC}

\section{Resumen}

Este artículo presenta la experiencia del diseño del curso "La danza folclórica como patrimonio", la cual es ofrecida a los estudiantes de pregrado de la Universidad del Cauca bajo la modalidad "massive online open course" (curso en línea masivo y abierto). También muestra los principales retos enfrentados en el ejercicio de integración de dos cursos presenciales, uno práctico y otro teórico, y su proceso de transformación a uno MOOC. El curso fue diseñado para tener dos créditos académicos y una dedicación semanal de seis horas y ofrecida como una electiva del componente de Formación Integral Social y Humana (FISH) a través de un espacio en la plataforma MOOC Open edX. Este proceso de integración de ambos cursos presenciales y su transformación en un MOOC trajeron consigo varios retos relacionados con el ajuste de contenidos, actividades académicas y evaluaciones. Este artículo muestra cómo fueron abordados estos retos en esta experiencia. Vale la pena mencionar que uno de los resultados obtenidos en esta investigación fue el primer curso de danza en modalidad MOOC en Latinoamérica, lo cual hace de esta una propuesta innovadora que permite el rescate de la cultura a través de la adaptación de los contenidos educativos tradicionales.

Palabras clave: patrimonio cultural; danza folclórica; curso masivo en línea; MOOC. 


\section{INTRODUCTION}

The "MOOCMenTES Project - Capacity Building for the Management of MOOCs for professional Training, Rural Development and New Generations of Rural Students in Improving their Transition to Higher Education", is developed by University of Cauca, and sponsored by the Colombian Ministry of National Education, within the framework of the Rural Plan for Higher Education for Rural Development and Peacebuilding [1]. The purpose of this project is the rural professional training in virtual environments and the transition to higher education from diverse rural contexts.

As a mediation strategy, and in order to reach the expected coverage of the project, it was agreed to create intensive contents in videos in MOOC/SPOC modality, oriented towards knowledge, promotion of rural development and production chains in universities, as well as its potential relationship to rural development in a context of diversity, nature, entrepreneurship and culture. To fulfill this goal, a series of online courses related to tourism and culture, among other topics.

To face this new challenge, the work team of the MOCMenTES project at University of Cauca, identified two in-person courses that work on cultural manifestations and contribute to the rescue and preservation of the culture in the state of Cauca: "Cultural Heritage" and "Recreational Folk Dance". These courses are offered by the programs of Tourism and Physical Education, respectively, and despite the fact of belonging to different programs and schools, and being taught by distinct teachers with unrelated academic backgrounds, both courses share the fact of working on cultural manifestations.

The "Recreational Folk Dance" course, is offered to undergraduate students from University of Cauca at Popayán, Santander de Quilichao, and El Bordo, as a subject of "Physical Education". This is a transversal course for all the undergraduate programs. Here, dance is approached from a practical and experiential perspective, which provides students with an opportunity for personal growth based on team work, exploration of playfulness, creativity and a basic dance component perspective, not from the technique, but from their own feelings as subjects where the corporeity and the motor skills are the foundational axes. This subject is developed in a rich cultural context, although a lack of knowledge about their cultural roots has been evidenced in the students. This has encouraged the rescue of identity through dance.

The "Cultural Heritage" course, is offered to students of the Tourism program at the School of Accounting, Economic and Administrative Sciences. It is characterized for dealing with conceptual foundations which aim at developing elements of judgment 
for the recognition, identification and valuation of the National Cultural Heritage, so students can project those elements in the design of specialized tourist products.

The common elements in the aforementioned courses are the cultural manifestations, since "Cultural Heritage" is approached from a theoretical perspective, recognizing that folk dances are one of these manifestations in the communities, and it is fundamental to recognize, rescue, conserve, and preserve them for future generations.

Given the characteristics of each of these courses and the elements that they have in common, it is possible to integrate them in just one massive online course, which would allow to expand coverage, as a contribution of the project MOCMenTES to the university.

The integration process of these two courses suggests a series of key elements, adaptations in the contents, activities and evaluation of the EDX platform where the courses will be designed and hosted. This process brings with it a series of challenges which are considered in this article.

\section{CHARACTERISTICS OF A MOOC}

MOOCs appeared in 2008 as the evolution of Open Educational Resources (OER),and are a proposal to universalize education and offer free and high-quality education to people who live in remote or disadvantaged areas. Inspired by Connectivism [2], an innovative educational theory proposed by George Siemens in 2005, MOOCs are characterized by offering free courses accessible through the Internet [3], from which a certificate of approval can be issued after payment [4], usually short-termed [5], focused on the contents -which must be open- basically of video type [6], complemented by other web-based learning activities, with relatively simple and automatic assessment activities [7], generally with no limit on the number of registered students [8] or with the ability to scale up to significantly high numbers of students.

In the creation process of this virtual course, it is important to consider that a MOOC (Massive Open Online Course) course is characterized for being offered through Internet platforms, generally with no prerequisites, and open to large numbers of students at a time [9]. Nowadays, MOOCs are a global phenomenon that is transforming teaching and making researchers reflect on new ways of learning in Higher Education Institutions (HEIs) worldwide. Since Dave Cormier coined the term MOOC in 2008, these courses have become the catalyst to change the traditional teaching/learning model of universities [10]. 


\section{METHODS}

\subsection{MOOC Design: "Folk Dance as Cultural Heritage"}

The MOOC Canvas proposed in [11] was used for the conception of the "Folk dance as cultural heritage" MOOC, as seen in figure 1 MOOC Canvas Project.

MOOC Canvas $\quad \begin{aligned} & \text { Design by: } \\ & \text { Date: } \\ & \text { Vols: }\end{aligned}$

Version:

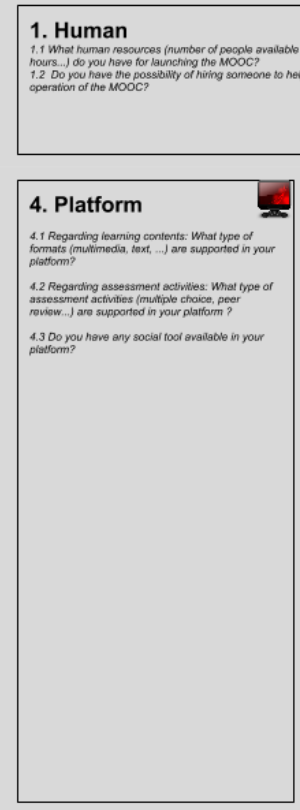

Available resources
5. General Description

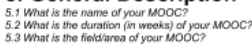

6. Target Learners

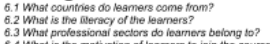

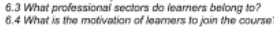
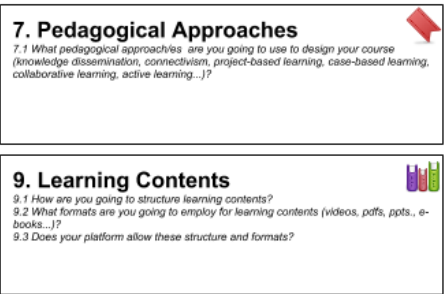

8. Objectives and Competences

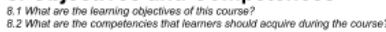

3. Equipment

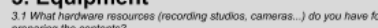

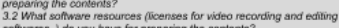

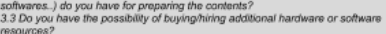

11. Complementary Technologies

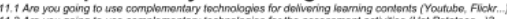

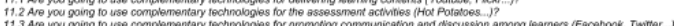

\section{Design decisions}

Figure 1. MOOC Canvas Project. Source: Proposal for a conceptual framework for educators to describe and design MOOCs

Source: [11]

\subsection{Definition and creation of contents}

For the specific design of the "Folk Dance as Cultural Heritage" MOOC, the guidelines proposed in [12] was followed. It is summarized below. According to the authors, a MOOC must:

- Facilitate the understanding of contextualized basic concepts.

- Promote the participation of students within the course activities. 
- Program the contents and learning activities in a progressive way, from the general to the particular.

- Define easily accessible and achievable contents and activities.

- Enable the increase of a significant number of students, including those who do not belong to this university.

Given that it is an integration of two in-person courses, a theoretical and a practical one, the work team defines that this MOOC must include the contents shown in figure 2. Contents of the "Folk dance as cultural heritage" MOOC course.

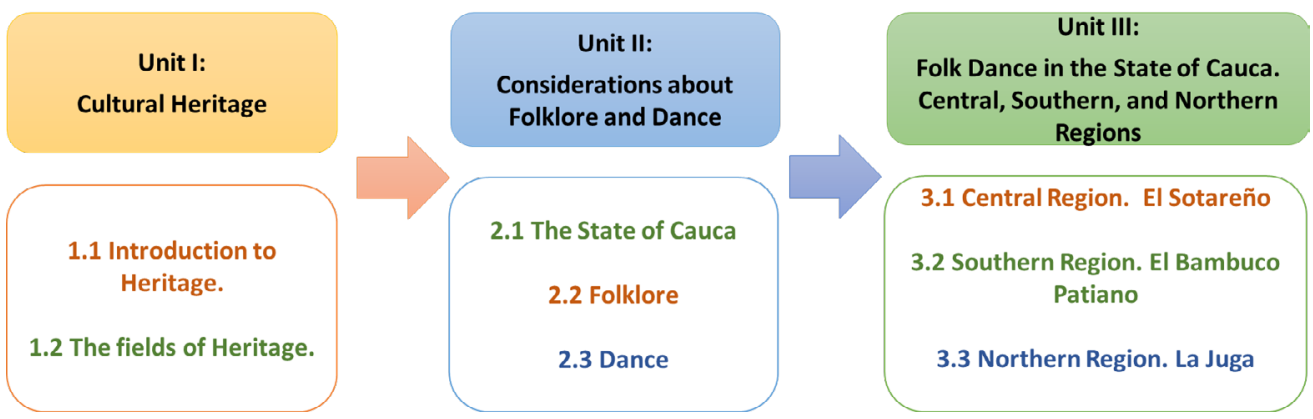

Figure 2. Contents of the "Folk dance as cultural heritage" MOOC course

Source: own elaboration

The Folk Dance as Cultural Heritage course consists of three units: 1) Cultural Heritage; 2) Considerations about folklore and dance, and 3) Folk Dance in the State of Cauca: Central, Southern, and Northern regions.

Unit I: "Cultural Heritage" discusses general concepts about cultural heritage, its definition, classification and assessment, so students can associate dance as a cultural manifestation which is part of the intangible cultural heritage, as defined by the United Nations Educational, Scientific and cultural organization (Unesco), cited by [13].

Unit II, Considerations about Folklore and dance, starts contextualizing the students about the University of Cauca, its geographical location and history, as well as the definition and classification of its cultural manifestations, folklore and dance.

At the end, there is a proposal to include a third unit entitled "Folk Dance in the State of Cauca: central, southern, and northern regions", which would include information about traditional dances delimited by regions due to the great multicultural wealth of this state. The selected dances for this unit would be: El Bambuco Patiano 
for the southern region, La Juga for the northern region, and El Sotareño for the central region. El Sotareño is a traditional dance from the capital city of the state. It would also include the history, costumes, music and choreography.

Considering that a MOOC is characterized for handling its contents in videos where teachers explain the topics of each unit, it is necessary to prepare the scripts to guide the teacher's speech for the final recording. Each video is intended to last from 1 to 3 minutes to ensure that the students do not lose interest or attention in the class. 58 videos were recorded for this course.

\subsection{Learning and evaluation activities}

The learning activities were adapted from the in-person courses to a virtual environment, considering the characteristics of the platform that will host the MOOC, keeping in mind, for instance, that the reading controls and the forums are non- gradable.

As the course is offered in a mass learning environment, the only feasible evaluation strategy is the one carried out through automatic grading services of the Open edX [14] platform. The basic guidelines for the design of the questionnaires were as follows:

- Questions should be consistent with the objectives formulated for the course.

- The mastery of comprehension and application skills should be verified according to Bloom's Taxonomy [15] rather than simple knowledge.

- Questions that can be answered with simple searches through an Internet browser should be avoided as far as possible.

- Three different questionnaires were done. Each one with at least 10 questions, which can be taken at three different times, in order to avoid fraud, or at least, to make it more difficult

\section{OUTCOMES}

\subsection{Learning outcomes in a Pilot test}

The Folk Dance as Cultural Heritage course is currently being developed as a pilot, a test of learning styles was applied to the students at the beginning of the course, and an exam was given at the end of the first unit (Introduction to Cultural heritage), to assess the learning results. These results were considered to design a 2.0 version of the course, in a way to explore a pedagogical impartiality concerning the learning styles. 
The use of the Open edX platform allows the obtention of statistical information, which is useful to understand the effect on learning of the strategy used for the design and delivery of the course. Figure 3 shows that women perform better than men.

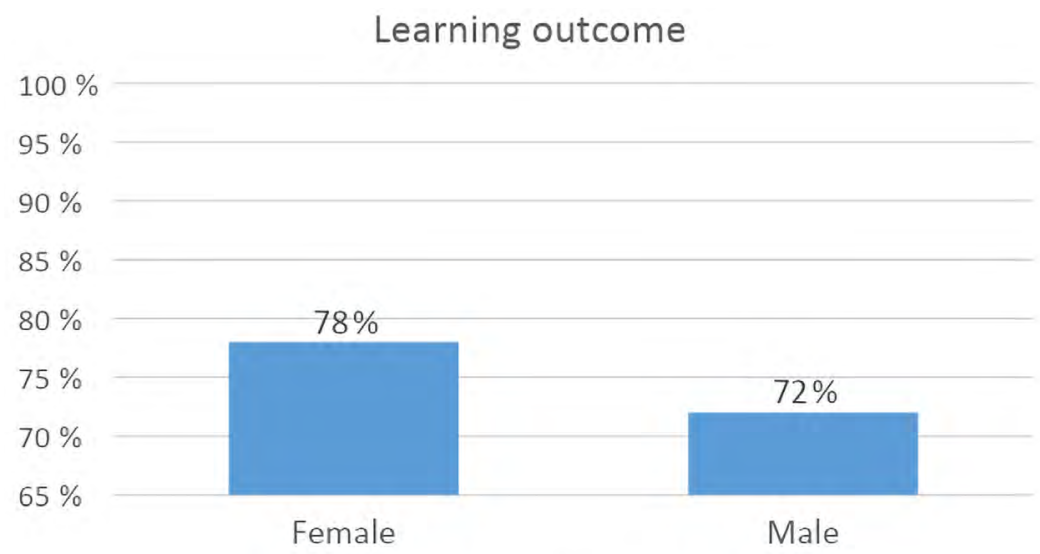

Gender

Figure 3. Learning outcomes vs. Gender.

Source: Taken from www.seleneunicauca.edu.co [16]

Figure 4 illustrates the development of some activities by the students. Out of 174 students registered for the course, 120 submitted an assessment. Out of that amount, 86 could be identified as having a basic learning preference according to Kolb Learning Styles Model [17]. 17 other students with the same characteristics did not respond to any exam. 20 students took the Kolb test but did not have an identifiable dominance.

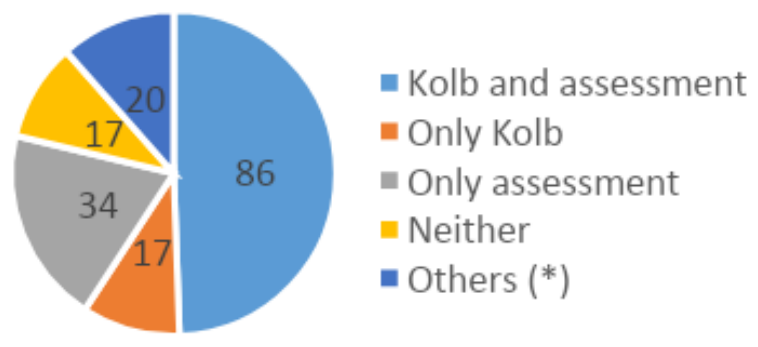

Figure 4. Development activities. Source: Taken from www.seleneunicauca.edu.co [16]

The Accommodator and Convergent learning styles were the most frequent (40 each), as shown in figure 5 . 


\section{Kolb Learning Style}

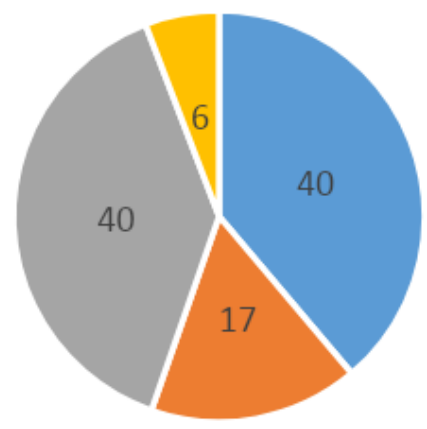

\section{" Accomodator $\|$ Assimilator $=$ Converger $\equiv$ Diverger}

Figure 5. Kolb Learning Styles distribution.

Source: Taken from www.seleneunicauca.edu.co [16]

Similarly, as shown in figure 6, the Convergent style followed by the Accommodator style were the best performers ( $78 \%$ and $76 \%$, respectively), followed by the Assimilator and Divergent style (70\%). This indicates that the course design is favoring students who prefer Active Experimentation as a form of information processing, according to Kolb's Model.

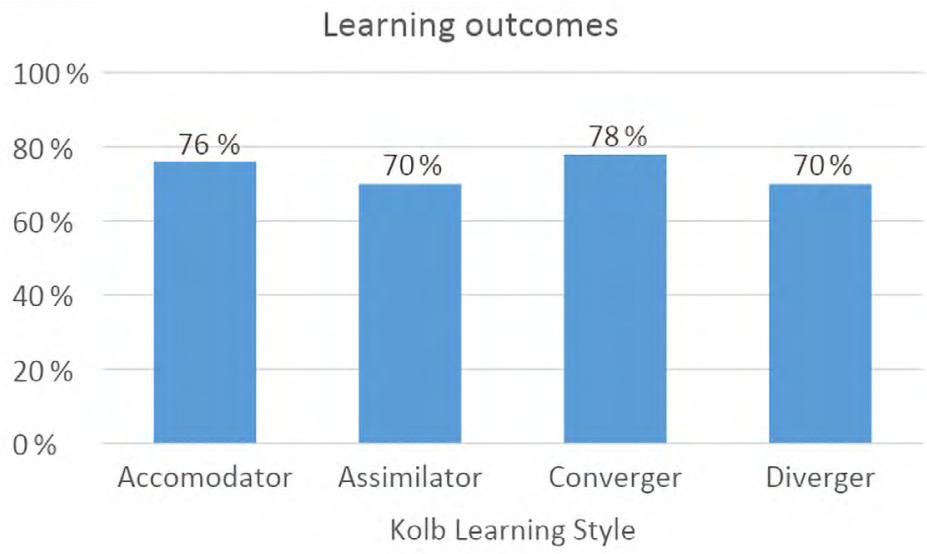

Figure 6. Learning outcomes vs. Kolb's Learning Style.

Source: Taken from www.seleneunicauca.edu.co. [16] 


\section{DISCUSSION}

\subsection{Challenges}

The experience of integrating two in-person courses, one theoretical and one practical, in order to create a virtual course, brought with it several challenges. One of the most complex challenges was related to seeing the teaching of folk dance from a different perspective to the traditional face-to-face modality as it has been offered so far at University of Cauca, which implies adjustments in its contents, activities and evaluation.

Considering the limitations of the platform in which the course will be hosted, and the characteristics of the contents that must be handled in a MOOC course, the dance topics will be approached from a theoretical perspective. It is here where another challenge arises: the construction of a theoretical base of the folk dance, since the courses of the "Physical Education" program are completely practical and experiential, so no theory is taught in them. During the search of theoretical references, it was found that some authors write about music, but not about dance, and there was no literature on folk dance in the State of Cauca. For this reason, the theoretical research was approached from the oral tradition of the inhabitants in each municipality where the subject is taught: Santander de Quilichao, Popayán and El Bordo (Patía). This situation made it difficult to select the theoretical topics about dance that were going to be taught in the course.

The adaptation of the practical contents of the dance course to theoretical contents that can be uploaded to the platform, required the recording of videos with the choreography and basic steps of each dance. This activity required a multidisciplinary team, including an instructional designer, two teachers of the course, a social communicator, an assistant in video production and postproduction, and a style corrector. This is how adapting in-person academic activities to a virtual learning environment became a challenge, but this was successfully faced and overcome. At the end, the course keeps all its contents in the platform (at present, the project is still at the video production phase of the last unit.) Nowadays, this course is offered to all the students at University of Cauca, including those living in rural areas, in the Selene platform (see figure 7). It currently has 175 registered students. At the end of the course, it will be possible to know whether the learning objectives were met. It is important to mention that the objectives are the same as in the in-person course; the only difference is the modality. 


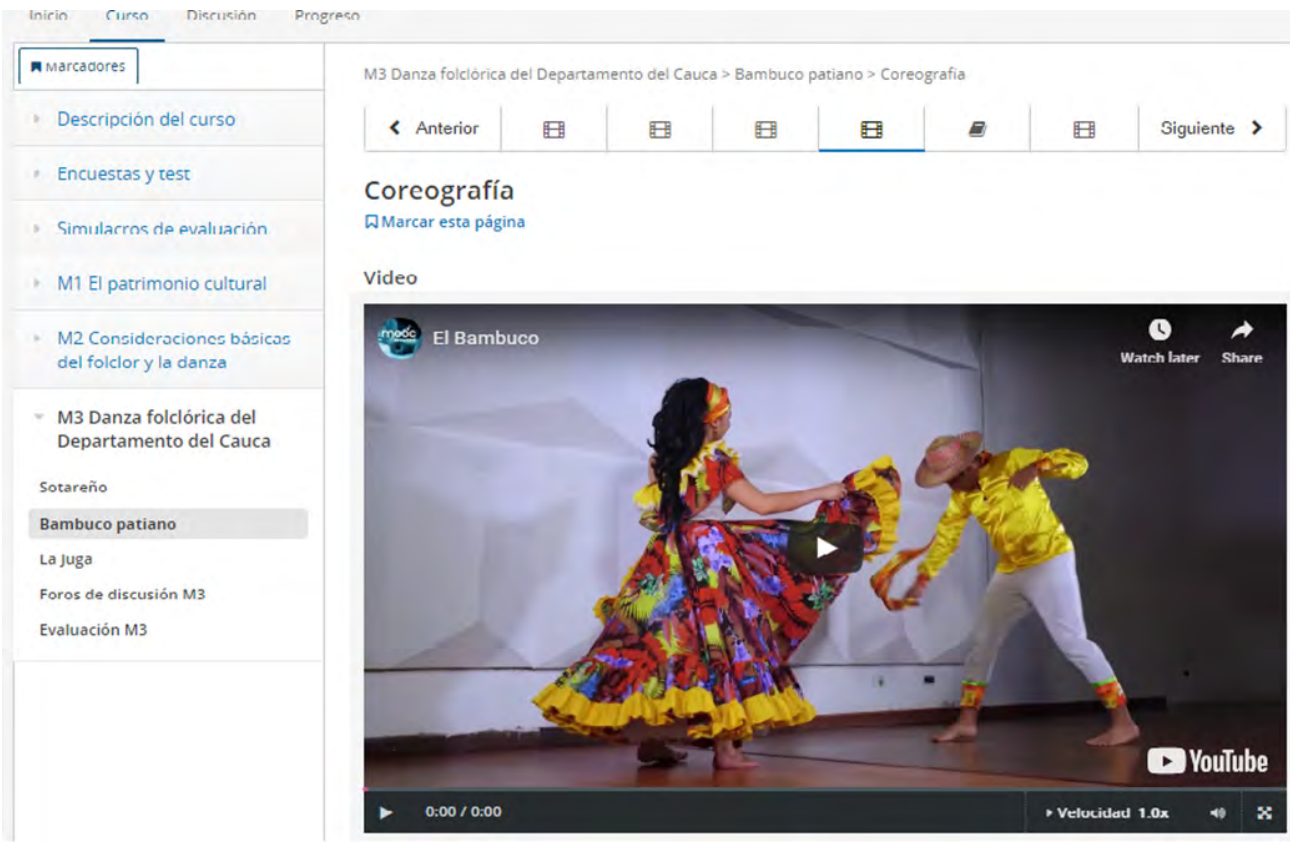

Figure 7. Course in Selene platform. Unicauca.

Source: Taken from www.seleneunicauca.edu.co [16]

Likewise, the evaluation also had to be changed, since in a practical course -such as Dance- the evaluation is qualitative, unlike the online courses that suggest a quantitative evaluation due to the large number of students registered for the class (around 200 students, on average). This is a quite challenging, since switching the way of evaluation implies the analysis of three fundamental aspects in online education: content and support materials, practical activities, and feedback communication, as mentioned by [18]. In this sense, the practical activities will be those allowed by the platform. No photographs or videos can be uploaded. Students will have to use external spaces to host their tasks and send the link to the tutor.

\section{CONCLUSIONS}

The online Folk Dance as Cultural Heritage course, within the framework of the MOOC Mentes project, has allowed University of Cauca to take advantage of the use of technology to expand the coverage of students with access to FISH electives. It offers greater flexibility in time management, a relevant feature in a virtual learning environment. 
The creation of this course allowed to make contents, such as dance, culture and heritage visible, thus contributing to the rescue, valuation, and preservation of the cultural roots of the State of Cauca, represented in its folk dances.

This course made it possible to move away from the traditional pedagogy of a face-to-face course and explore new teaching/learning models in a virtual environment, which required adaptation and, in this case, the transformation of contents that had been practical until now, in order to take them to the theoretical realm, based on literature on this subject that is scarce and explicitly non-existing for this region.

The experience of content creation made visible one of the most relevant elements in virtual education: that the technical resources necessary for the production of the course videos are numerous, although they may seem scarce and simple when seen from the students' perspective. The production requires an incalculable effort by an entire team, which leads us to consider that the design and assembly of an online course requires a greater effort in time and physical resources compared to a face-to-face course.

\section{ACKNOWLEDGEMENTS}

This article has been supported by the "MOOC MenTES Project - Capacity Building for the Management of MOOC for Vocational Training, Rural Development and New Generations of Rural Students in Improving their Transition to Higher Education", co-financed by the Ministry of National Education of the Republic of Colombia, within the framework of the Rural Plan for Higher Education for Rural Development and Peace building (VRI 49694, 2018).

\section{REFERENCES}

[1] Universidad del Cauca, "MOOC MenTES | Inicio,” Mooc Mentes, 2018. https://www.unicauca. edu.co/moocmentes/ (accessed Dec. 14, 2020).

[2] G. Siemens, "Connectivism: a learning theory for the digital age. e-Learning Library," Retrieved Sept, vol. 24, 2018, pp. 1-8, 2014.

[3] D. Wiley, "The MOOC Misnomer - iterating toward openness," 2012. https://opencontent. org/blog/archives/2436 (accessed Dec. 14, 2020).

[4] A. McAuley, B. Stewart, G. Siemens and D. Cormier, "The MOOC model for digital practice," 2010 .

[5] T. R. Liyanagunawardena, A. A. Adams and S. A. Williams, "MOOCs: A systematic study of the published literature 2008-2012," Int. Rev. Res. Open Distrib. Learn., vol. 14, no. 3, pp. 202-227, 2013. 
[6] P. J. Guo, J. Kim and R. Rubin, "How video production affects student engagement: An empirical study of MOOC videos," in Proceedings of the first ACM conference on Learning@, scale conference, 2014, pp. 41-50.

[7] R. Roig-Vila, S. Mengual Andrés and C. Suárez Guerrero, "Evaluación de la calidad pedagógica de los MOOC," 2014.

[8] D. Jansen and R. Schuwer, "Institutional MOOC strategies in Europe," Status Rep. Based Mapp. Surv. Conduct. Oct.-Dec. 2014, 2015.

[9] M. Solarte, G. A. Ramírez and D. A. Jaramillo, "Hábitos de ingreso y resultados en las evaluaciones en cursos en línea masivos con reconocimiento académico," Ing. E Innov., vol. $5,1,2017$.

[10] M. Sanagustín, J. Maldonado and N. Morales, "Estado del arte de adopción de MOOCs en la Educación Superior en América Latina y Europa," MOOC-Mak. Constr. Manag. Capacit. MOOCs High. Educ. MOOC-Mak. Recuperado de: http://www. mooc-maker. org/wp-content/ files/WPD1. 1_ESPAOL. pdf.

[11] C. Alario-Hoyos, M. Pérez Sanagustín, D. Cormier and C. Delgado Kloos, "Proposal for a conceptual framework for educators to describe and design MOOCs," 2014.

[12] J. R. Drake, M. O'Hara and E. Seeman, "Five principles for MOOC design: With a case study,” J. Inf. Technol. Educ. Innov. Pract., vol. 14, 14, pp. 125-143, 2015.

[13] O. L. Molano, “Identidad cultural un concepto que evoluciona.," Rev. Opera, no. 7, pp. 69-84, 2007.

[14] D. Jaramillo-Morillo, M. Solarte, G. R. González and M. Pérez-Sanagustín, "Follow-up of learning activities in open edx: A case study at the university of cauca," in European Conference on Massive Open Online Courses, 2017, pp. 217-222.

[15] M. Forehand, “Bloom's taxonomy,” Emerg. Perspect. Learn. Teach. Technol., vol. 41, no. 4, pp. 47-56, 2010.

[16] Universidad del Cauca, "MOOC| Unicauca," MOOC Unicauca. http://selene.unicauca.edu. co/ (accessed Dec. 14, 2020).

[17] D. A. Kolb, Experiential learning: Experience as the source of learning and development. FT press, 2014.

[18] M. Mayorga Fernández and D. Madrid Vivar, "Metodología de evaluación de los cursos on line,” Didáctica Innov. Multimed., 20, pp. 0001-12, 2011. 